\title{
La fortaleza de los llanos de Bonda. Conquista de una frontera del reino español en el siglo XVI
}

Resumen: Este artículo se enmarca en el proceso colonizador del reino español en América durante el siglo XVI, período en el que las fortificaciones jugaron un papel fundamental en el control y expansión del territorio. Se expone el caso particular de una casa fuerte que existió en el territorio de Santa Marta, donde las tribus indígenas opusieron gran resistencia a la conquista. Para reconstruir el escenario y significado de esta y otras edificaciones, se consultaron fuentes primarias de archivo, textos académicos y se realizó trabajo de campo en la zona de estudio. Como resultado surge nueva información sobre la historia de las relaciones sociales en Santa Marta.

Palabras clave: colonia, frontera, guerra, defensa, indios americanos.

\section{The Bonda plains fortress. Conquest of a spanish realm frontier in the 16th century}

Abstract: This article contributes to the understanding of the colonizing process of the Spanish kingdom in America during the sixteenth century, when fortifications played a fundamental role in the control and expansion of conquered territory. It presents the particular case of a strong house that existed in the territory of Santa Marta, where the indigenous populations strongly opposed the conquest. The article uses archival sources, academic texts, and fieldwork to reconstruct the meaning of this and other buildings in the area of study, presenting new information on the history of social relations in Santa Marta.

Keywords: colony, frontier, war, defense, american indians.

\section{A fortificação das planícies de Bonda. Conquista de uma fronteira do reino espanhol no século XVI}

Resumo: Este artigo parte do enquadramento do processo de colonização do reino espanhol na América durante o século XVI, período no qual, as fortificações desempenharam um papel fundamental no controle e expansão do território. Observa-se o caso particular de uma "casa forte" que existiu no território de Santa Marta, onde tribos indígenas opuseram uma grande resistência à conquista. Para reconstruir o cenário e o significado desta e de outras edificações, foram consultadas fontes primárias de arquivos, textos acadêmicos e trabalho de campo no local. Como resultado, surge uma nova informação sobre a história das relações sociais em Santa Marta.

Palavras-chave: colônia, fronteira, guerra, defesa, índios americanos.

Cómo citar este artículo: Eduardo Mazuera Nieto, "La fortaleza de los Ilanos de Bonda. Conquista de una frontera del reino español en el siglo XVI”, Trashumante. Revista Americana de Historia Socia/13 [2019]: 56-83.

DOI: 10.17533/udea.trahs.n13a03

Fecha de recepción: 9 de marzo de 2018

Fecha de aprobación: 14 de agosto de 2018

Eduardo Mazuera Nieto: Magíster en Historia por la Universidad de los Andes. Máster en Restauración y Rehabilitación del Patrimonio por la Universidad Alcalá de Henares. Actualmente es profesor asistente del departamento de Arquitectura de la Universidad de los Andes.

Correo electrónico: emazuera@uniandes.edu.co 


\title{
La fortaleza de los llanos de Bonda. Conquista de una frontera del reino español en el siglo XVI
}

\author{
Eduardo Mazuera Nieto
}

\section{Introducción}

$E_{\mathrm{c}}$ ta investigación aporta al conocimiento de la historia de Santa Marta durante sus primeras fortificaciones. Dichos edificios, hasta ahora poco relevantes en la historiografia de esta ciudad, se presentan aquí como protagonistas en el conflicto bélico, desde las cuales se puede hacer una lectura de las relaciones y significados a través de la arquitectura y de su ubicación en el territorio. Es posible analizar la denominada "fortaleza de los llanos de Bonda" como un elemento estratégico que afecta la forma en que se ha entendido hasta ahora la interacción de los españoles en la ciudad de Santa Marta con los indígenas de la Sierra Nevada y con la Corona española durante el siglo XVI. Este artículo deriva de una investigación que pretendió establecer la relación del edificio con su entorno desde la consideración de su forma, localización y significado. Asimismo, indagó sobre las aparentes incongruencias entre la representación gráfica de la fortaleza y la evidencia física de la ruina arquitectónica que parece corresponder a esta, con el objeto de identificar las posibles justificaciones. ${ }^{1}$ El artículo aboga por la relevancia estratégica, política, simbólica y discursiva de la fortaleza de los llanos de Bonda.

Se consultaron documentos que dan cuenta de los acontecimientos asociados directa e indirectamente a la fortaleza estudiada. ${ }^{2}$ También se revisaron los escritos

* Artículo derivado de la tesis de maestría en Historia, Eduardo Mazuera Nieto, "La fortaleza de los llanos de Bonda. Relación entre edificio y entorno en la frontera de Santa Marta en el siglo XVI" (Tesis de maestría en Historia, Universidad de los Andes, 2014). Agradezco de manera muy especial a la directora de la tesis, la doctora Marta Herrera Ángel, al lector externo, doctor Santiago Giraldo Peláez, y al grupo de investigación Taller Umbra, quienes aportaron valiosos comentarios e indicaciones para la elaboración del texto. Adicionalmente, agradezco al Instituto Colombiano de Antropología e Historia (ICANH) por la beca de investigación para financiar el trabajo de campo en el área de estudio y la consulta de archivos en España (2013).

1. Mazuera, "La fortaleza de los llanos de Bonda".

2. En Santa Marta se consultaron el Archivo Histórico del Magdalena y el Archivo Histórico Eclesiástico de la Antigua Provincia de Santa Marta, pero solo tienen información posterior al siglo XVII. 
de quienes visitaron la ciudad de Santa Marta durante el siglo XVI y describieron los eventos que allí sucedieron, así como textos posteriores que se basaron en las narraciones de sus antecesores o se apoyaron en relatos de informantes con memoria de los acontecimientos. ${ }^{3}$ Estudios más recientes ahondan en el tema y analizan el papel de las fortificaciones, así como el conflicto entre españoles e indígenas.

Lo anterior se complementó mediante técnicas de trabajo de campo que permitieron identificar una ruina arquitectónica al parecer correspondiente a la fortaleza en cuestión. Adicionalmente, se establecieron comparaciones entre este edificio y otros análogos, todo dentro del respectivo contexto histórico. Por último, se interpretaron citas y términos encontrados en las fuentes para explicar el significado de los hechos acontecidos y construidos.

Para comenzar, es pertinente señalar que la frontera del reino español en el norte de África es considerada análoga a la establecida en América, pues allí se intentó defender las tierras ocupadas por medio de fortificaciones establecidas en los territorios circundantes. ${ }^{4}$ Estos fuertes y torres de vigilancia fueron ideados para defenderse más de los beduinos, calificados como "bárbaros" y "reputados como la gente más indómita de África", 5 que de los enemigos europeos. Dicha experiencia en el mar Mediterráneo constituyó un antecedente para la forma en que se fortificaron las

3. El cronista Gonzalo Fernández de Oviedo, en compañía de Pedrarias Dávila, permaneció en Santa Marta pocos días en 1514, pero aportó un detallado capítulo sobre la región, los nativos y las actividades de españoles. Gonzalo Fernández de Oviedo, Historia general y natural de las Indias, islas y Tierra-Firme del mar océano (Madrid: Editorial Bruño, 1991). Juan de Castellanos estuvo con Alonso Luis de Lugo, Pedro de Ursúa y Gonzalo Jiménez de Quesada en algunas exploraciones y registró su experiencia en la obra de 1586. Juan de Castellanos, Elegías de varones ilustres de Indias (Bogotá: Editorial Gerardo Rivas Moreno, 1997). Fray Pedro de Aguado llegó a las Indias hacia 1573 y en su obra de 1581 incluyó el capítulo "Conquista y población de Santa Marta y Nuevo Reino de Granada”. Fray Pedro de Aguado, Recopilación historial (Bogotá: Imprenta Nacional, 1906); Antonio de Herrera y Tordesillas, Historia general de los hechos de los castellanos en las islas y Tierra Firme del mar océano (Asunción: Editorial Guaranía, 1944); Fray Pedro Simón, Noticias historiales de las conquistas de Tierra Firme en las Indias Occidentales (Bogotá:Talleres Gráficos Banco Popular, 1981); Fernández de Piedrahíta, Historia general de las conquistas del Nuevo Reino de Granada (Cali: Editorial Carvajal, 1987); Antonio Julián, La Perla de la América, Provincia de Santa Marta (Bogotá: Academia Colombiana de Historia, 1980).

4. Gregorio Sánchez Doncel, La presencia de España en Orán (1509-1792) (Toledo: Estudio Teológico de San Ildefonso, 1991) 17-18, 124-125, 221; Leonardo Villena, "Libros sobre fortificaciones: la circulación de los saberes técnicos", Las fortificaciones de Carlos V, coord. Carlos José Hernando Sánchez (Madrid: Ediciones del Umbral, 2000) 272, 282. Los "presidios" fueron un tipo de fortificación española, derivada de los fuertes fronterizos del Imperio Romano, que constituyeron una cadena de puestos de avanzada militar para la expansión en el norte de África. Fernand Braudel, El Mediterráneo y el mundo mediterráneo en la época de Felipe II (México: Fondo de Cultura Económica, 2010) 270-271; Antonio Bravo Nieto y Jesús M. Sáez Cazorla, Melilla en el siglo XVI a través de sus fortificaciones (Melilla: Servicio de Publicaciones del Ayuntamiento / Fundación Municipal Socio-Cultural, 1988).

5. Juan Bautista Vilar, Mapas, planos y fortificaciones hispánicos de Libia (1510-1911) (Madrid:Agencia Española de Cooperación Internacional, 1997) 44-49. 
fronteras marítimas de ultramar. ${ }^{6}$ Durante el siglo XVI España contó con varias plazas fuertes $-\mathrm{O}$ asentamientos fortificados - en los litorales de los territorios ocupados. Estas fueron importantes por servir de "cabezas de puente" para iniciar proyectos de expansión, brindar estabilidad y seguridad. ${ }^{7}$ Su funcionamiento dependía del respaldo eficaz y oportuno que recibían de la nación a la cual pertenecían, lo que era fundamental para garantizar el éxito de la expansión. ${ }^{8}$

Desde estos centros urbanos se coordinó la construcción de pequeñas fortificaciones como casas fuertes o torres de vigilancia que funcionaron de manera similar a las atalayas construidas por los árabes durante su ocupación de la península ibérica (711-1492), que los cristianos copiaron o reutilizaron para fines similares de vigilancia y defensa, o resguardo de quienes regresaban de incursiones en tierras de enemigos durante la Edad Media. Estos edificios se ubicaban en territorio fronterizo y tenían la importancia de estar en lugares estratégicos de conexión con reinos contiguos donde había intereses comerciales. Funcionaron como parte de un sistema donde podían estar separados por cortas distancias — aproximadamente $10 \mathrm{~km}$ - para permitir la comunicación entre ellos mediante mensajes de alarma con señales de fuego y humo. ${ }^{9}$ Algunos también sirvieron más para proteger rutas y asentamientos que para dominar territorios en conflicto. En el norte de África pequeños fuertes españoles o "presidios" ayudaron a controlar a las tribus beduinas y a proteger la costa de posibles invasiones provenientes de Bizancio. ${ }^{10}$ De la misma forma, desde los fuertes que se erigieron en la costa española mediterránea se vigilaron las vías que comunicaban hacia el norte, por la amenaza de desembarcos enemigos. ${ }^{11}$ En resumen, se considera que los fuertes de tamaño pequeño cumplían un rol fundamental en la articulación de los territorios objeto de invasión

6. Alicia Cámara y Fernando Cobos, "La experiencia de la monarquía española en la fortificación marítima del Meditarráneo y su proyección en el Caribe" (Actas del Congreso Internacional Fortificación y Frontera Marítima, Ajuntament d'Eivissa, 2005) 1-2.

7. Ciudades como One u Honein, Mazalquivir, Orán, Burgía y Trípoli, entre otras ciudades en el norte de África, fueron ocupadas por España en el siglo XVI. Juan Bautista Vilar, Mapas, planos y fortificaciones hispánicos de Túnez (S XVI-XIX) (Madrid: Instituto de Cooperación con el Mundo Árabe, 1991) 100 y 133. Las "plazas fuertes" sirvieron a la política expansionista de España en el intento de dominar a las "políticamente invertebradas tribus marroquíes". Antonio Sánchez-Gijón, "La Goleta, Bona, Bugía y África. Los presidios del Reino de Túnez en la política mediterránea del emperador", Las fortificaciones de Carlos V, coord. Carlos José Hernando Sánchez (Madrid: Ediciones del Umbral, 2000) 625-626.

8. R. Brian Ferguson y Niel L. Whitehead, War in the Tribal Zone, Expanding States and Indigenous Warfare (Santa Fe: School of American Research Press, 1992) 7, 18-19.

9. Basilio Pavón Maldonado, Tratado de arquitectura hispanomusulmana, vol. 2 (Madrid: Consejo Superior de Investigaciones Científicas, 1999) 288-291.

10. Cámara y Cobos 3.

11. Oleg Grabar, "La arquitectura del poder: palacios, alcazabas y fortificaciones", La arquitectura del mundo islámico, su historia y significado social, ed. George Michell (Madrid: Alianza,1985) 66. 
por parte de los peninsulares. De manera similar, en la conquista del Nuevo Mundo las casas fuertes sirvieron para dominar a los "indios". ${ }^{2}$

\section{Las casas fuertes en Santa Marta}

Mediante cédula real del rey Carlos I de España, fechada el 6 de noviembre de 1524, don Rodrigo de Bastidas recibió instrucciones para fundar en el Nuevo Mundo la ciudad de Santa Marta y construir allí una fortificación para defenderse de los indígenas. ${ }^{13}$ Los ataques y resistencia de la población nativa fueron comunes ante la llegada de los españoles, puesto que los últimos se consideraron con el derecho de expropiar las riquezas y tierras a los indígenas y justificaron su esclavitud. ${ }^{14}$ Bastidas llegó en 1526 con los títulos de "Gobernador, Adelantado y Capitán General” para fundar la ciudad de Santa Marta, que se ubicó desde sus inicios frente a la bahía denominada la Caldera, de condiciones óptimas para la creación de un puerto. ${ }^{15}$

Inicialmente, la defensa de la ciudad sobre el frente marino recayó en una sola fortaleza: la casa fuerte de la playa de Santa Ana, construida en 1529. ${ }^{16}$ El gobernador García de Lerma inició en 1532 la construcción de una nueva fortaleza de piedra en el mismo lugar que la anterior, pero no logró terminarla debido a que los canteros traídos de España para este propósito abandonaron su labor para dedicarse a robar los contenidos de tumbas indígenas. En 1536, por orden del adelantado Pedro Fernández de Lugo, continuó esta construcción de la cual se tiene muy poca información. El gobernador Luis de Manjarrés reconoció la necesidad de edificar una nueva casa fuerte que se inició en 1561, pero tras un ataque de indígenas que la dejó en ruinas fue demolida durante la administración de Martín de las Alas

12. El término "indios" se refiere a las comunidades prehispánicas. El empleo de esta palabra se deriva de su común aplicación en las fuentes consultadas y de su reconocimiento en el vocabulario español del siglo XVI. Algunas definiciones: "Indio, el natural de la India." "India, Hay Indias Orientales y Occidentales; de la mayor parte de ambas y de lo descubierto dellas es señor la majestad del rey Filipo tercero...". Sebastián de Covarrubias Orozco, Tesoro de la lengua castellana o española (Madrid: Editorial Castalia, 1995) 665.

13. Ernesto Restrepo Tirado, Historia de la provincia de Santa Marta (Bogotá: Biblioteca de Autores Colombianos / Editorial ABC, 1953) 32.

14. Anthony Pagden, Spanish Imperialism and the Political Imagination. Studies in European and SpanishAmerican Social and Political Theory 1513-1830 (New Haven:Yale University Press, 1990) 13-36.

15. La primera expedición de conquistadores en llegar a la región de Santa Marta estaba encabezada por Rodrigo de Bastidas (1501) y no se tiene registro de enfrentamientos violentos con los nativos. Según el registro histórico, el desembarco de Rodrigo Henríquez Colmenares (1510) fue la primera confrontación violenta de los españoles con los indios de esta zona. Pedro Arias Dávila encabezó una nueva incursión en el territorio indígena (1514); desembarcó esta vez en la bahía de la futura fundación de Santa Marta donde encontró a su llegada un recibimiento hostil.Véase Hermes Tovar, Relaciones y visitas a los Andes. Siglo XVI. Región Caribe, t. 2 (Bogotá: Colcultura, 1993) 50-51; Joaquín Acosta, Historia de la Nueva Granada (Medellín: Editorial Bedout, 1971) 29; De Herrera y Tordesillas 81 .

16. Arturo Bermúdez Bermúdez, Materiales para la historia de Santa Marta (Bogotá: Banco Central Hipotecario / Editorial L. Canal y Asociados, 1981) 223-234. 
(1565-1569). ${ }^{17}$ En 1572, el entonces gobernador Luis de Rojas reconstruyó la casa fuerte a "cuatro cuadras" al norte del lugar donde se edificó la original, según las necesidades comunicadas al rey Felipe II:

La disposicion desta Çiudad y Puerto della ser tan ynportanisimo al servicio de V[uestra] M[ajestad] rreal y á q.e. se guarden y defiendan q. ay en ella solamente diezV[ecin]os y muy povres y alcanzados á causa de ser rrovados muchas vezes de corsarios Françeses Enemigos y de las coyunturas q. se ofreçen en tanto defienden esta Çiudad y Puerto deV[uestra] M[ajestad] como muy buenos y leales bazallos y en esta forma Çiudad y Puerto no ay defensa ninguna ny Fortaleza en donde los V[ecin]os con sus personas, mujeres é hijos se puedan defender de los enemigos. ${ }^{18}$

Un dibujo de 1573 es la representación o scenografía de esta fortificación en el cual aparece una torre rectangular entre dos construcciones más bajas con la leyenda "el pueblo", ${ }^{19}$ que le da la espalda a la bahía en la cual se aprecia "el morro grande", característico del puerto de Santa Marta (Figura 1). La apariencia del edificio representado es una muestra de la resonancia de modelos medievales, aún vigentes en el siglo XVI. ${ }^{20}$ Es notorio el contraste de tamaños entre la torre y las casas del pueblo dibujadas: la fortificación representada era casi diez veces más alta que las construcciones vecinas. Sin embargo, es poco probable que así fuera dado el limitado presupuesto de la ciudad y las múltiples necesidades que revelan las fuentes consultadas. ${ }^{21} \mathrm{La}$ construcción de las fortalezas españolas en Santa Marta durante el siglo XVI era una necesidad, debido a que en varias oportunidades sus habitantes estuvieron en condiciones desfavorables de defensa por falta de soldados o por falta de dinero para pagarles a estos por su labor.

Hacia la misma época de la mencionada fortaleza de Santa Ana, el gobernador Fernández de Lugo ordenó en 1536 la construcción de un fuerte de madera en los

17. Restrepo 219-220; Juan Manuel Zapatero, Historia de las fortalezas de Santa Marta y estudio asesor para su restauración (Bogotá: Academia Colombiana de Historia / Carlos Valencia Editores, 1980) 61-62; Trinidad Miranda Vásquez, La Gobernación de Santa Marta (1570-1670) (Sevilla: Escuela de Estudios Hispanoamericanos, 1976) 110.

18. "Carta del gobernador Luis de Rojas", Santa Marta, 20 de abril de 1573. AGI, Sevilla, Santa Fe, 49, r. 8, n. 26, f. 1 v.

19. El término scenografía fue empleado en el siglo XVI para hacer referencia a este tipo de dibujos que representan volúmenes arquitectónicos en tres dimensiones, al combinar proyecciones en planta (ichonographia) y alzado (orthographia).Véase Pedro Mora Piris, "Arte y técnica en la fortificación", Las fortificaciones de Carlos V, coord. Carlos José Hernando Sánchez (Madrid: Ediciones del Umbral, 2000) 169; Enrique Marco Dorta, Historia del arte hispanoamericano, t. 1 (Barcelona: Salvat Editores, 1956) 588-592; José María Gentil Baldrich, "La interpretación de la 'scenografia' vitrubiana o una disputa renacentista sobre el dibujo del proyecto", EGA: Revista de Expresión Gráfica Arquitectónica 1 (1993): 15-33.

20. Ramón Gutiérrez, Fortificaciones en Iberoamérica (Madrid: Fundación Iberdrola / Ediciones El Viso, 2005) 265-266.

21. "Carta del gobernador Luis de Rojas", Santa Marta, 17 de enero de 1573. AGI, Sevilla, Santa Fe, 49, r. 8, n. 23 , ff. $1 v-2$ v. 
Figura 1. "Modelo de la fortaleza que sea de hazer en Santa Marta"

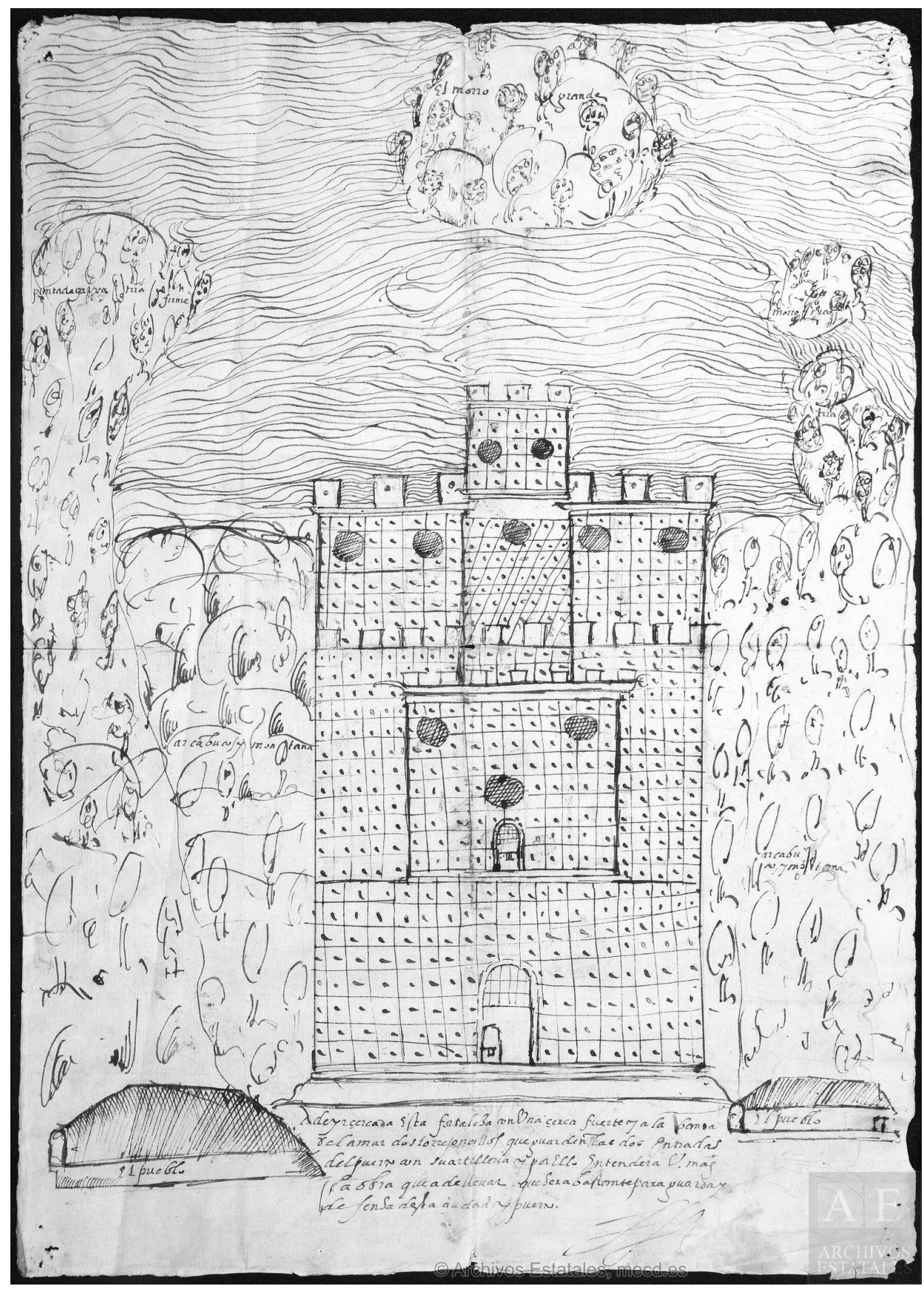

Fuente: Ministerio de Cultura y Deporte. AGI, Sevilla, MP-Panamá, 4, f. 1. 
Figura 2. Mapa del sector noroccidental de la Sierra Nevada de Santa Marta en el siglo XVI

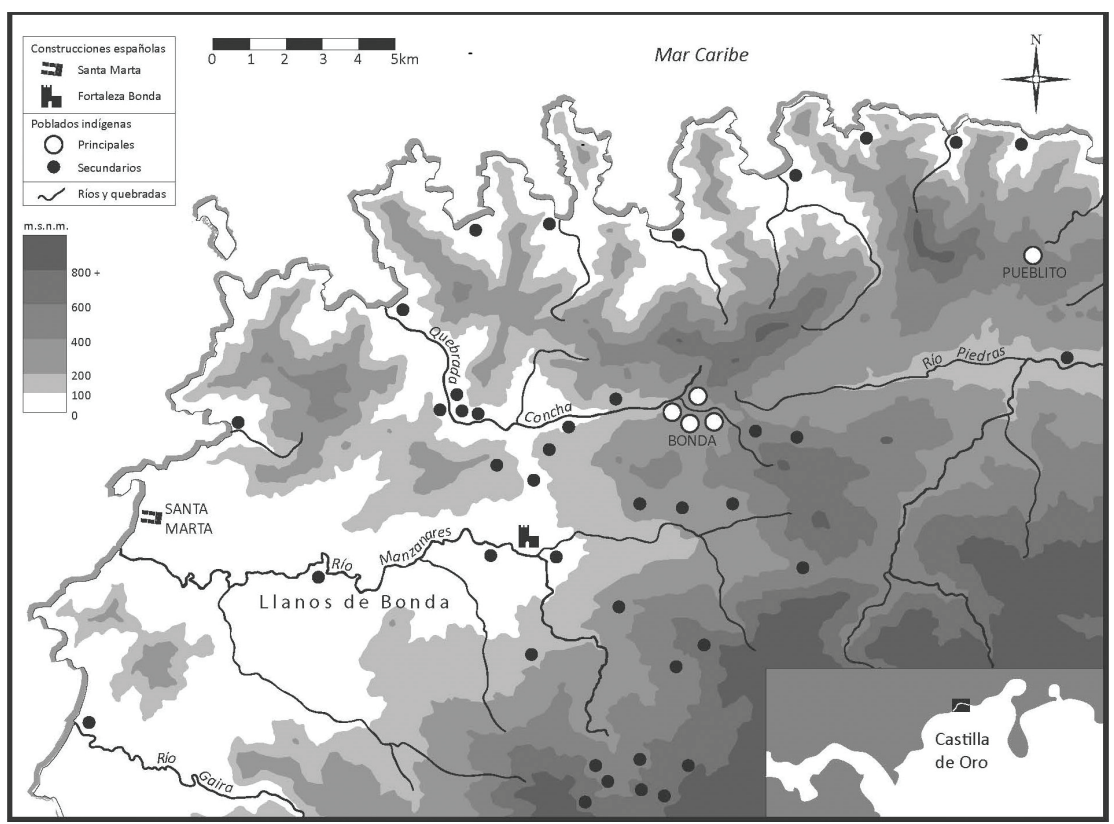

Fuente: Elaboración propia con base en Gilberto Cadavid y Luisa Fernanda Herrera, "Manifestaciones culturales en el área Tayrona", Informes Antropológicos 1 (1985): 5-44, y el trabajo de campo del autor realizado entre 2012 y 2014.

"llanos de Bonda" para contrarrestar los ataques provenientes del oriente de Santa Marta y establecer un puesto de control en el territorio indígena donde se encontraba buena parte de los cultivos que abastecían a la ciudad. El fuerte no volvió a ser mencionado en el registro histórico hasta que en 1557 el gobernador Luis de Manjarrés construyó una nueva fortaleza en el mismo sector para que sirviera de lugar de descanso y refugio a los soldados españoles expedicionarios en la región. ${ }^{22}$ Es interesante destacar que a pesar de varios fracasos ocurridos en este lugar se dieron sucesivas construcciones de la casa fuerte, lo cual sugiere que su ubicación era de importancia estratégica (Figura 2).

En 1572 el gobernador Luis de Rojas ordenó la construcción de una nueva casa fuerte en el mismo lugar que la estructura de madera anterior, "a cuatro leguas" de la ciudad, pero esta vez en piedra. ${ }^{23}$ Durante los cuatro meses y medio que se invirtieron en la obra trabajó un equipo de constructores compuesto por un maestro mayor y albañil, tres carpinteros, un herrero y un cantero que labró los escudos de armas. Además, doscientos soldados debieron trabajar sin alejarse de

22. Bermúdez 220.

23. Miranda 109-112; Zapatero 73. 
sus armas, debido a los frecuentes ataques de los indígenas que aparecían sorpresivamente. $^{24}$

La construcción culminó el mismo año tras reunir 2,500 pesos que los españoles recuperaron de un galeón hundido en el puerto. Esta suma podría equivaler a un poco menos de la mitad del costo total de la construcción, si se tiene como referencia otros gastos similares de la época. ${ }^{25}$ Finalmente, Rojas informa que: "La Fortaleza tengo ya acavada y muy mejor de lo questava antes sin la qual esta Ciudad no se puede sustentar, cuyo modelo enbio con esta". ${ }^{26}$

En el AGI se conserva el dibujo — " "modelo" enviado por Luis de Rojas en 1572 - que representa a la fortaleza de los llanos de Bonda (Figura 3). Esta representación gráfica contrasta por sus pocos detalles con la rigurosa planimetría técnica elaborada para otras fortificaciones de las colonias españolas en el Caribe de esa misma época. ${ }^{27}$ En el dibujo es posible observar que el edificio fue representado como una torre principal con puertas reforzadas, el escudo de Castilla y León, cañones, y rodeada por una muralla de un solo nivel de altura. ${ }^{28}$ En el volumen principal se representan aspilleras — delgadas ranuras verticales - en la fachada y "almenas" piramidales que rematan la torre con un estilo "mudéjar" característico de algunas construcciones españolas del siglo XVI en América, ${ }^{29}$ como resonancia de la prolongada ocupación árabe en la península ibérica. ${ }^{30}$

\section{El entorno físico, social e imaginario}

Las menciones encontradas sobre la fortaleza de Bonda describen su ubicación en un terreno calificado como "llano", término que según el diccionario de Sebastián de Covarrubias se define como "lo que está igual y tendido como campo llano y camino llano". En otras palabras, una superficie plana y contraria a la topografia definida como "sierra" que "se llama tierra montañosa y desigual, que en sus peñascos resquebrajados semeja a los dientes de la sierra instrumento". ${ }^{31}$

\section{Bermúdez 220-221; Zapatero 79.}

25. Bermúdez 221, 229; "Carta del gobernador Luis de Rojas”, Santa Marta, 20 de abril de 1573. AGI, Sevilla, Santa Fe, 49, r.8, n.25, ff. 1v.

26. "Carta del gobernador Luis de Rojas", Santa Marta, 30 de septiembre de 1572. AGI, Sevilla, Santa Fe, 49, r. 8 , n. 21, f. 1v.

27. Alicia Cámara, Fortificación y ciudad en los reinos de Felipe II (Madrid: Nerea, 1998) 201.

28. Bermúdez 220-223.

29. También se podría utilizar el término "merlones" por corresponder a una época en la cual ya existía la artillería de cañones.

30. El arte mudéjar en la arquitectura es un estilo que se desarrolló en los reinos cristianos de la península ibérica con elementos hispanomusulmanes, como testimonio de la ocupación árabe. Muchas construcciones españolas del siglo XVI en América se caracterizaron por este estilo. Véase, por ejemplo, Ramón Gutiérrez y Rodrigo Gutiérrez, Historia del arte iberoamericano (Barcelona: Lunwerg, 2000) 27; Fernando Chueca Goitia, Invariantes castizos de la arquitectura española (Madrid: Dossat, 1981) 170-179; Pavón 287-288.

31. De Covarrubias 723 y 894 . 
Figura 3. "Modelo" de la fortaleza de los llanos de Bonda

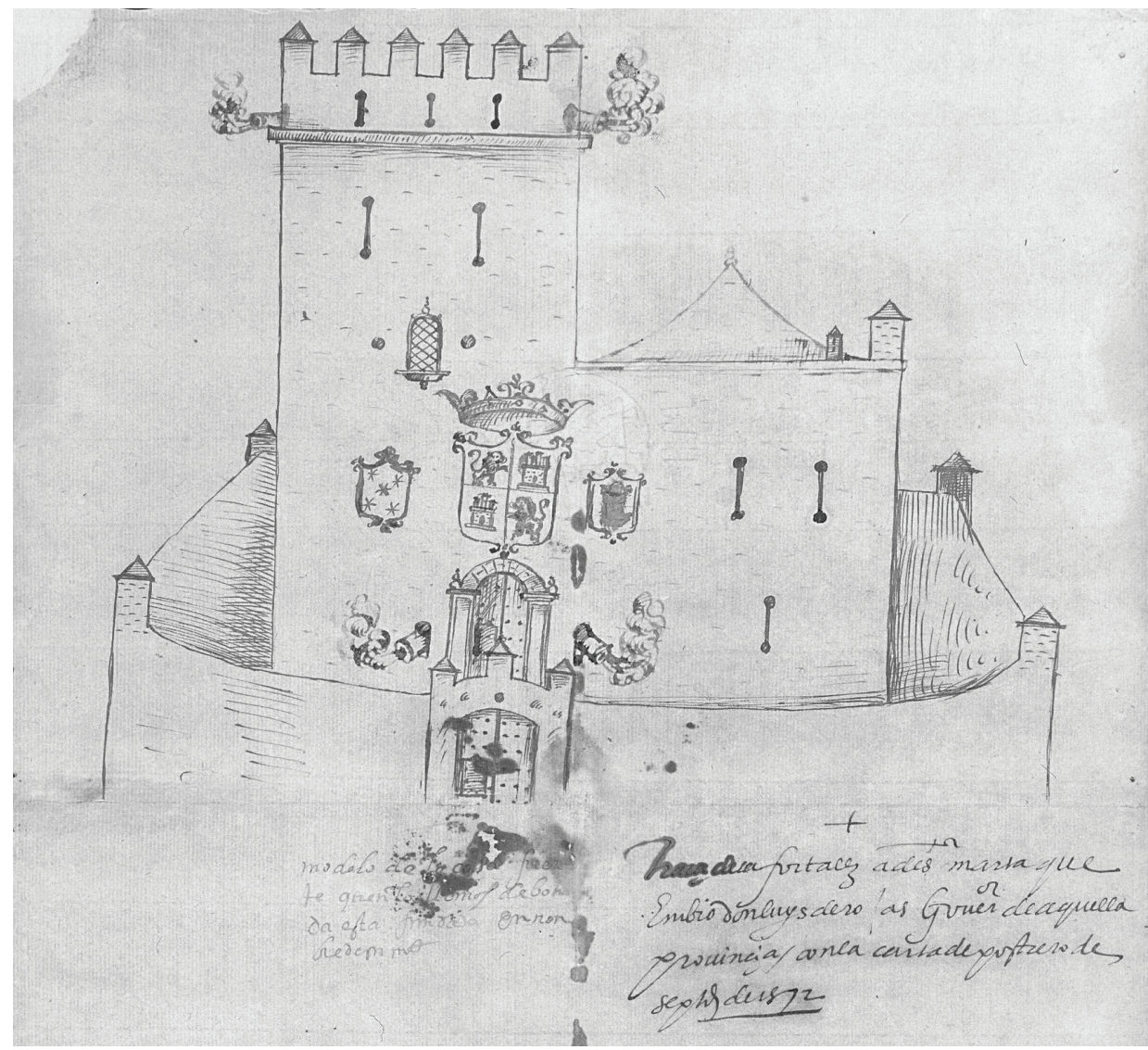

Fuente: "Traça de la fortaleza de Santa Marta que enbio don Luys de Rojas Gouernador de aquella provincia con la carta de postrero de septiembre de 1572", Santa Marta, 30 de septiembre de 1572. Ministerio de Cultura y Deporte. AGI, Sevilla, MP-Panamá, 3, f. 1.

El término "monte" o "montaña" podía referirse a elevaciones del terreno, pero también a un área cubierta de vegetación, lo que tenía una connotación de peligro por su irregularidad y dificultad para transitarla, con un contenido sorpresa donde un atacante podía esconderse y luego huir. Marta Herrera Ángel señala que la "montaña" podía representar lo inculto o fuera de control; un "lugar de perdición" donde habitaban los hombres en estado "salvaje" e indisciplinado. ${ }^{32}$ En cambio, la tierra "llana" representaba menos riesgos y era posible ver hasta cierta distancia los alrededores. ${ }^{33}$

32. Marta Herrera Ángel, Ordenar para controlar. ordenamiento espacial y control político en las llanuras del Caribe y en los Andes centrales neogranadinos. Siglo XVIII (Medellín: La Carreta, 2007) 49-53.

33. Bernardo de Vargas Machuca, Milicia y descripción de las Indias (Bogotá: Biblioteca Banco Popular, 2003) 145. 
Aquí es evidente cómo en el imaginario español de la conquista hay una diferenciación entre "orden" y "desorden" social que incluso se ve reflejada en su apreciación de la geografia y la forma de habitarla. El término "salvaje” se refiere a "todo lo que es de la montaña” y por "bárbaro" identifica a "los que son ignorantes sin letras, a los de malas costumbres y mal morigerados, a los esquivos que no admiten la comunicación de los demás hombres de razón, que viven sin ella, llevados de sus apetitos, y finalmente los que son despiadados y crueles". ${ }^{34}$ Los indios eran vistos como bárbaros y salvajes en la "sierra" en donde eludían el régimen español que pretendía controlarlos. En 1572 el gobernador de Santa Marta, Luis de Rojas, le escribió al rey Felipe II sobre su propósito de controlar a los indios: “...yo confío en nuestro señor que dentro del mes de mayo los tendré a todos llanos y en servidumbre..." ${ }^{35}$ Esta expectativa de pacificar el territorio en el corto plazo tardó hasta finales del siglo XVI.

En un plano de 1551 se representa a la ciudad de Santa Marta con la plaza principal, que se abre en el costado occidental hacia la playa, rodeada de casas. También hay iglesias, un convento y el entorno de la ciudad, y se incluye el río Manzanares y la bahía del puerto con la formación rocosa de "El Morro" que surge del agua. Alrededor de la ciudad en zonas despejadas del dibujo se lee la palabra "llano" y luego en la periferia del plano aparecen líneas curvas irregulares que corresponden a las elevaciones de terreno y a la vegetación circundante. Aquí contrasta fuertemente la geometría rígida de la traza urbana en el "llano" con la representación errática del entorno "salvaje” y aún sin domesticar (Figura 4).

Los "llanos de Bonda" se encuentran en la franja alargada de tierra que se proyecta hacia el oriente de la ciudad hasta una distancia de $12 \mathrm{~km}$, donde la inclinación del terreno comienza a pronunciarse en las faldas de la Sierra Nevada. ${ }^{36} \mathrm{Al}$ norte del llano se encuentra el pequeño valle de Quebrada Concha y en la parte alta de la cuenca se ubicaba la antigua población de los indios Bonda hasta finales del siglo XVI ${ }^{37}$ En el extremo oriental del llano, el río Manzanares desciende de la sierra, corre hacia el occidente por la llanura y desemboca en el mar Caribe, al sur del centro fundacional de Santa Marta. El sur del llano está delimitado por las estribaciones de la Sierra Nevada. El límite occidental está constituido por la ciudad de Santa Marta, la bahía del puerto y el cerro que conduce al valle del río Gaira, hacia el sur (Figura 2).

En 2012 se recorrió el sector denominado "los llanos de Bonda" con el propósito de encontrar vestigios de la fortaleza en cuestión. Las fuentes la ubican en terreno "llano", a "cuatro leguas" en dirección oriente de Santa Marta y "media

34. De Covarrubias 166, 320 y 880.

35. "Carta del gobernador Luis de Rojas", Santa Marta, 20 de abril de 1572. AGI, Sevilla, Santa Fe, 49 , r. 8, n. 25 , f. 2 r.

36. Instituto Geográfico Agustín Codazzi. http://ssiglwps.igac.gov.co/ssigl2.0/visor/galeria. req?mapaId=19 (10/01/2014).

37. Gilberto Cadavid y Luisa Fernanda Herrera, "Manifestaciones culturales en el área Tayrona", Informes Antropológicos 1 (1985):39-40. 


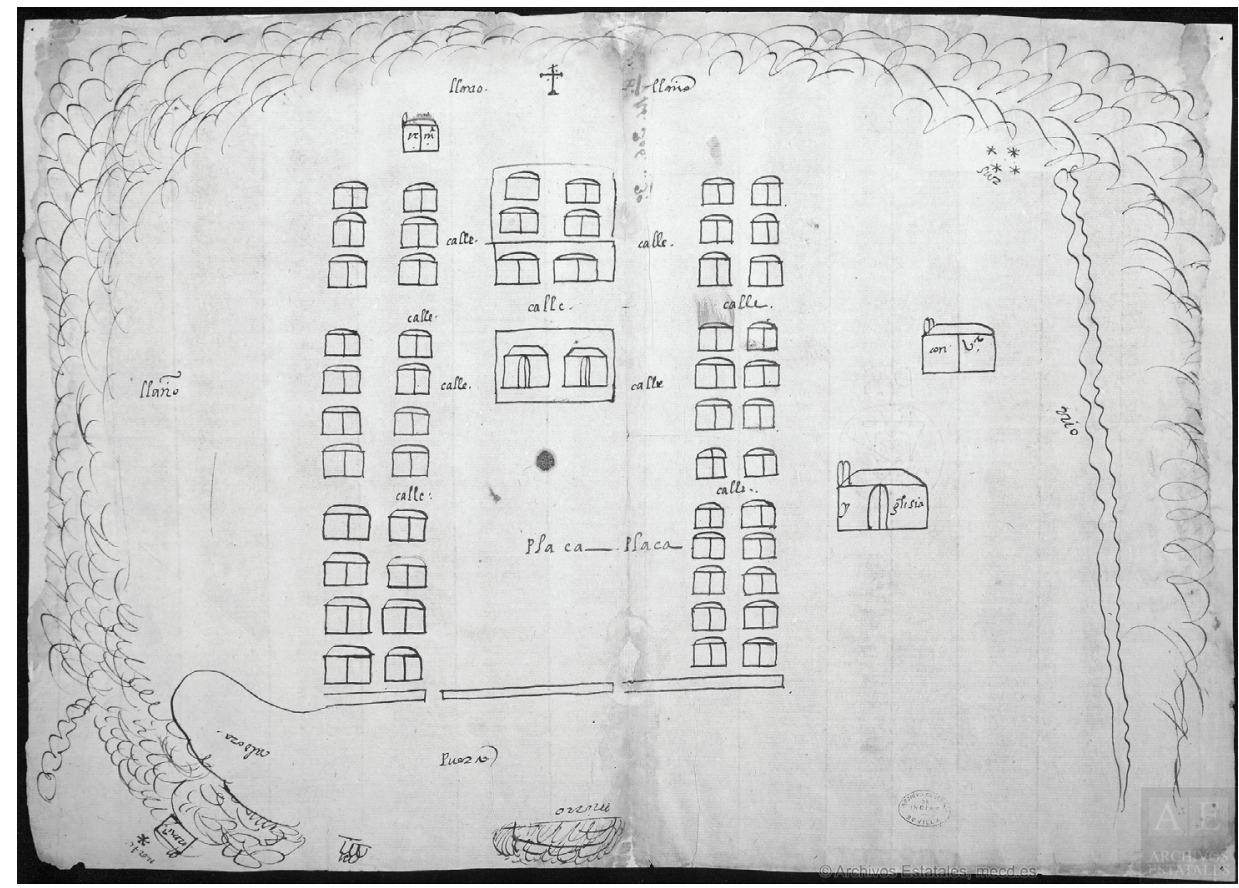

Fuente: Ministerio de Cultura y Deporte. AGI, Sevilla, MP-Panamá, 273, f. 1.

legua" antes de llegar a la antigua población indígena de Bonda. ${ }^{38} \mathrm{La}$ conversión de cuatro leguas castellanas del siglo XVI resulta en una distancia de 10 a $12 \mathrm{~km}$, según los documentos consultados. ${ }^{39}$ Estos datos resultaron en la delimitación de un polígono de reconocimiento para la búsqueda de algún vestigio del edificio (Figura 5).

Como resultado, fue hallada una ruina a $11 \mathrm{~km}$ al oriente de Santa Marta con muros en piedra de hasta $70 \mathrm{~cm}$ de altura y en promedio $70 \mathrm{~cm}$ de espesor, que conforman dos cuadriláteros adyacentes -o rectángulo- de $7,7 \mathrm{~m}$ por $17,7 \mathrm{~m}$ en los bordes interiores. Pilas de piedras — aparentemente escombros de paredes derruidas - rodean el sitio, junto a fragmentos de tejas de barro cocido. Ladrillos de $28,50 \times 14,50 \times 5,50 \mathrm{~cm}$ enmarcan las aperturas de dos puertas (Figura 6).$^{40} \mathrm{Al}$

38. "Carta de García de Lerma”, Santa Marta, 9 de septiembre de 1532.AGI, Sevilla, Santa Fe, 49, r. 1, n. 4, f. 1v; "Carta del Cabildo Secular de Santa Marta", Santa Marta, 15 de enero de 1574.AGI, Sevilla, Santa Fe, 66, n. 13, f. 1r; "Carta del gobernador Luis de Rojas", Santa Marta, 30 de septiembre de 1572. AGI, Sevilla, Santa Fe, 49, r.8, n.21, f. 1r; Miranda 109-112; Zapatero 73.

39. De Covarrubias 707, 754 y 807; Real Academia Española, Diccionario de Autoridades (Madrid: Editorial Gredos, 1963) 380.

40. Una investigación arqueológica reciente en Santa María de la Antigua del Darién — fundación española, 1510, Golfo de Urabá-, registra ladrillos que se asemejan a los encontrados en la ruina de los llanos de Bonda. Alberto Sarcina, "Santa María de la Antigua del Darién, delimitación de 
Figura 5. Plano del área de búsqueda [zona sombreada]

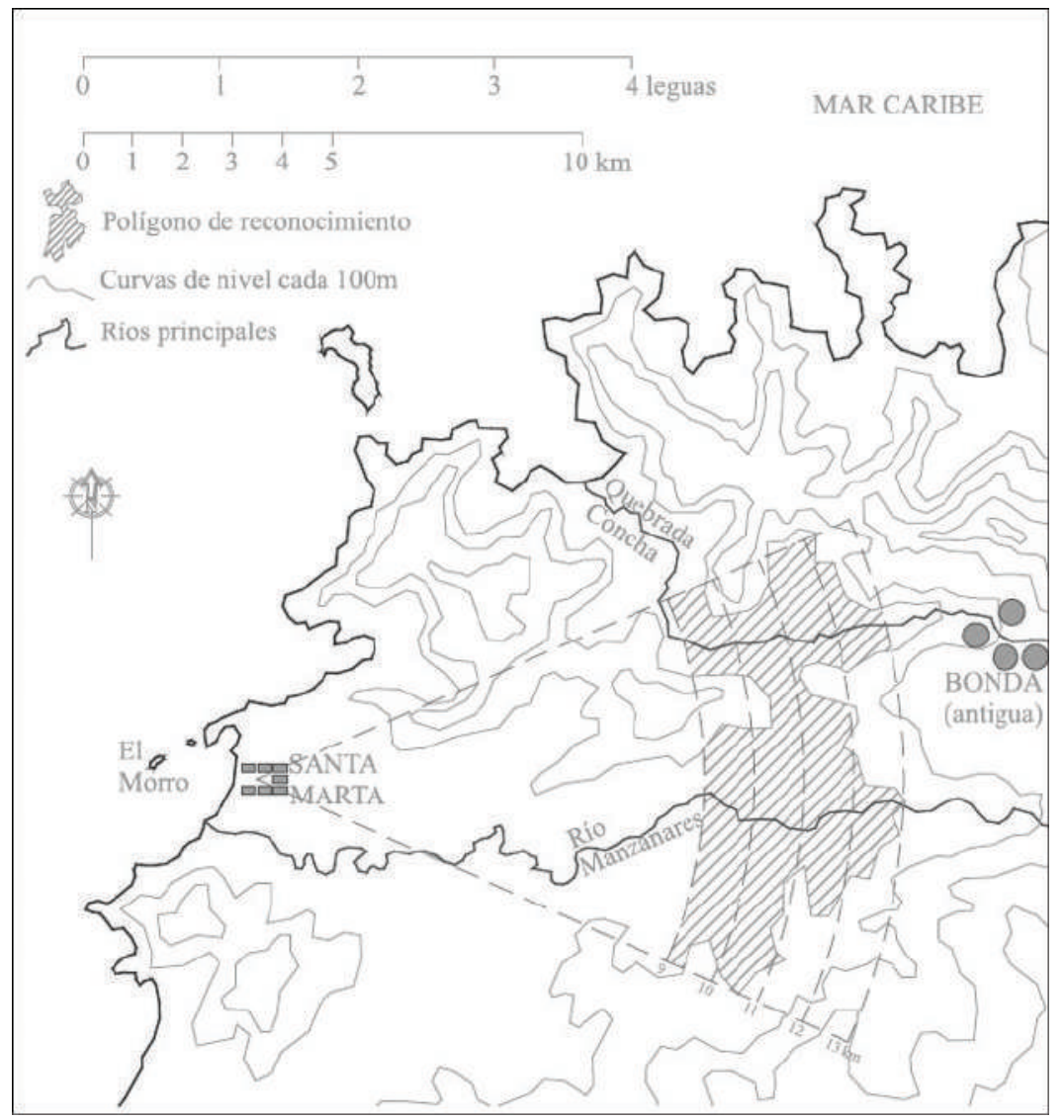

Fuente: Elaboración propia. El oriente se definió según las posiciones extremas de la salida de sol en los solsticios.

comparar la evidencia fisica de la ruina con el dibujo de 1572 que representa a la fortaleza de los llanos de Bonda hay coincidencias en la geometría, distribución de espacios, volúmenes diferenciados, ubicación de la puerta de acceso y dimensiones aproximadas del ancho del edificio (Figura 7).

Sin embargo, un análisis más detallado revela que la scenografía no resulta ser una representación precisa de la ruina, por inconsistencias en la relación entre el ancho de los muros encontrados $(70 \mathrm{~cm})$ frente a la altura del edificio dibujado $(16 \mathrm{~m}$ aproximadamente). La investigación reveló que, dadas las proporciones y técnica constructiva, los muros apenas podrían tener $7 \mathrm{~m}$ de altura. ${ }^{41}$ Adicionalmente, el

la ciudad y nuevos hallazgos arqueológicos" (Conferencia, Museo del Oro, 2014).

41. Jean Coignet y Laurent Coignet, Restaurar una casa antigua. Construcción, diagnóstico, intervenciones (Barcelona: Ediciones Ceac, 2006) 30-35; Antonio Perla y Ana Yáñez, Manual de conservación de casas históricas y singulares (Barcelona:Tusquets, 2005) 61-73; Heinrich Schmitt y Andreas Heene, Tratado de construcción (Barcelona: Gustavo Gili, 2002) 163-171. 
Figura 6. Estructura rectangular encontrada en los "llanos de Bonda"

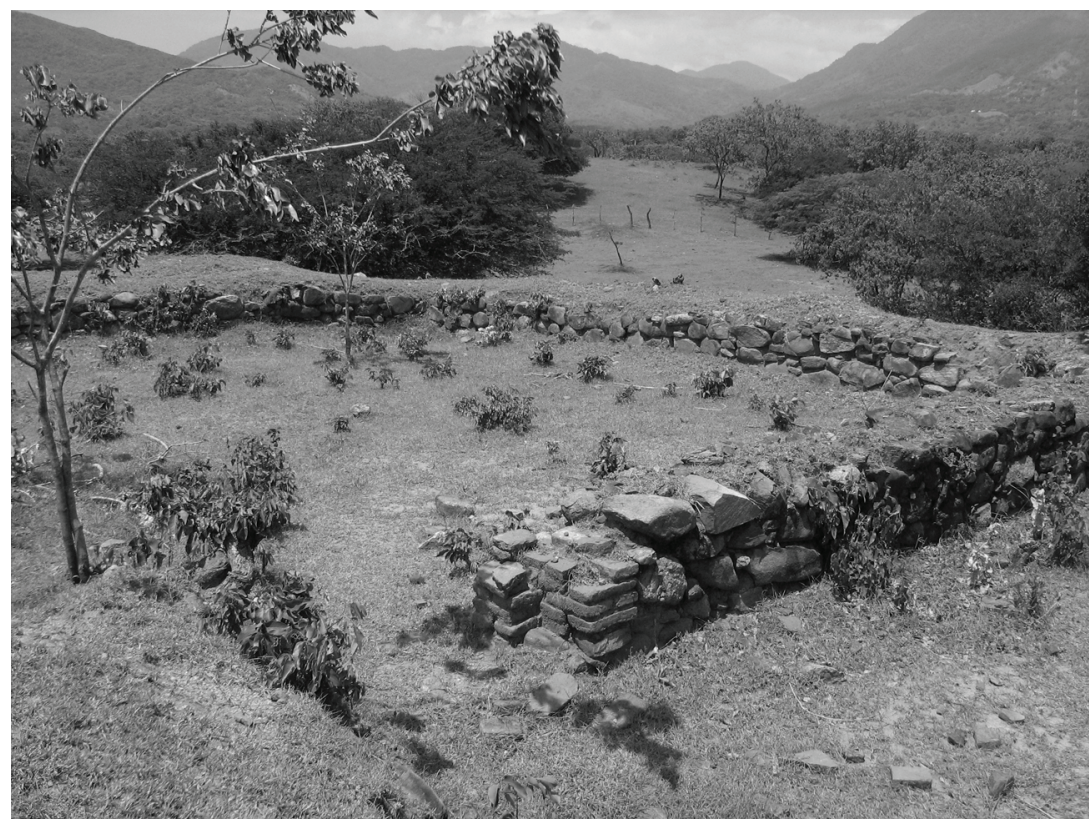

Fuente: Coordenadas: $11^{\circ} 14^{\prime} 19.43^{\prime \prime}$ N, 740 06’55.30” O. Fotografia del autor, julio 2012.

volumen de escombros corresponde a la cantidad de material que compondría una construcción de 4 a $5 \mathrm{~m}$ de altura. ${ }^{42}$ De haber tenido $16 \mathrm{~m}$ de altura, los muros tendrían que tener el doble del espesor y los escombros serían tres o cuatro veces más voluminosos que los existentes.

Por otro lado, no hay rastros de la muralla perimetral que aparece en el dibujo. Es posible que fuera una empalizada de madera que desapareció con el paso del tiempo, cuyas marcas de postes solo podrían ser detectadas mediante una excavación arqueológica. La reja metálica, los tres escudos y las dovelas del arco sobre la puerta son elementos que requirieron para su elaboración una mano de obra especializada y costosa, algo poco factible dada la precariedad del caso. De haber existido, probablemente fueron retirados del lugar en el momento del ataque indígena (1572) o de la demolición (1577). ${ }^{43}$

Un referente arquitectónico análogo a la fortaleza de los llanos de Bonda es la Torre del Homenaje en Santo Domingo (Figura 8), inicialmente construida para defenderse de los indios que amenazaban dicha ciudad. Tiene 19,3 m de altura y 14 $\mathrm{m}$ de ancho, similar a las dimensiones interpretadas en la scenografía de la fortaleza

42. Se calculó el volumen aproximado de escombros y suma aproximadamente $150 \mathrm{~m}^{3}$, que distribuidos en los $62 \mathrm{~m}$ lineales de muros con $70 \mathrm{~cm}$ de ancho que tiene la ruina alcanzan para 3,45 $\mathrm{m}$ de altura (adicionales a los $70 \mathrm{~cm}$ de muro en pie y posiblemente $40 \mathrm{~cm}$ más hasta la base del muro bajo el sedimento de tierra).

43. Bermúdez 221; Zapatero 79. 
Figura 7. Comparación de la scenografía de la fortaleza de Bonda [1572] y el levantamiento de la ruina encontrada [2012]
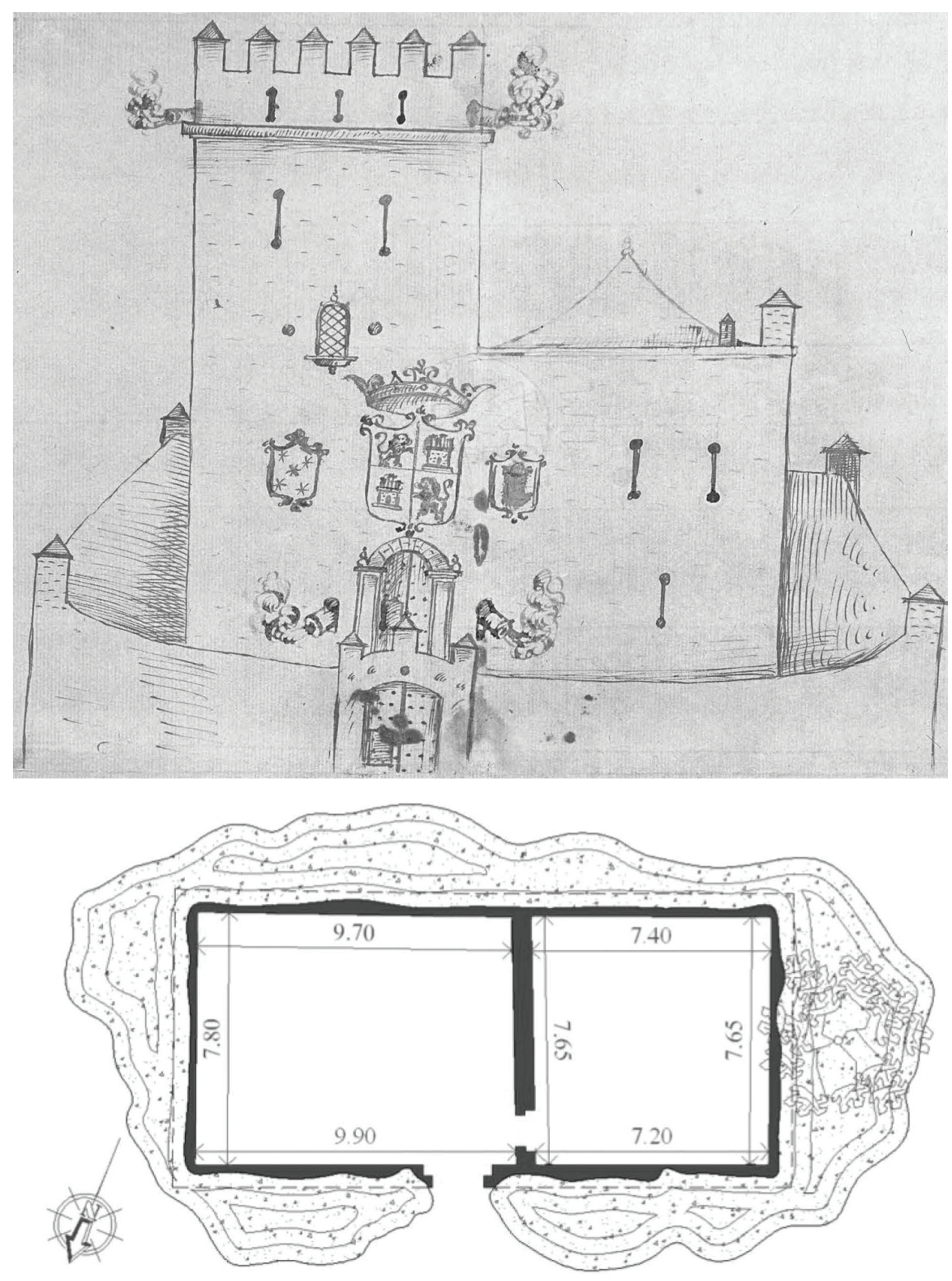

Fuente: Elaboración propia con base en Ministerio de Cultura y Deporte.AGI, Sevilla, MP-Panamá,3,f.1. 
Figura 8. Fotografía y levantamiento arquitectónico [planta y corte] de la Torre del Homenaje en Santo Domingo
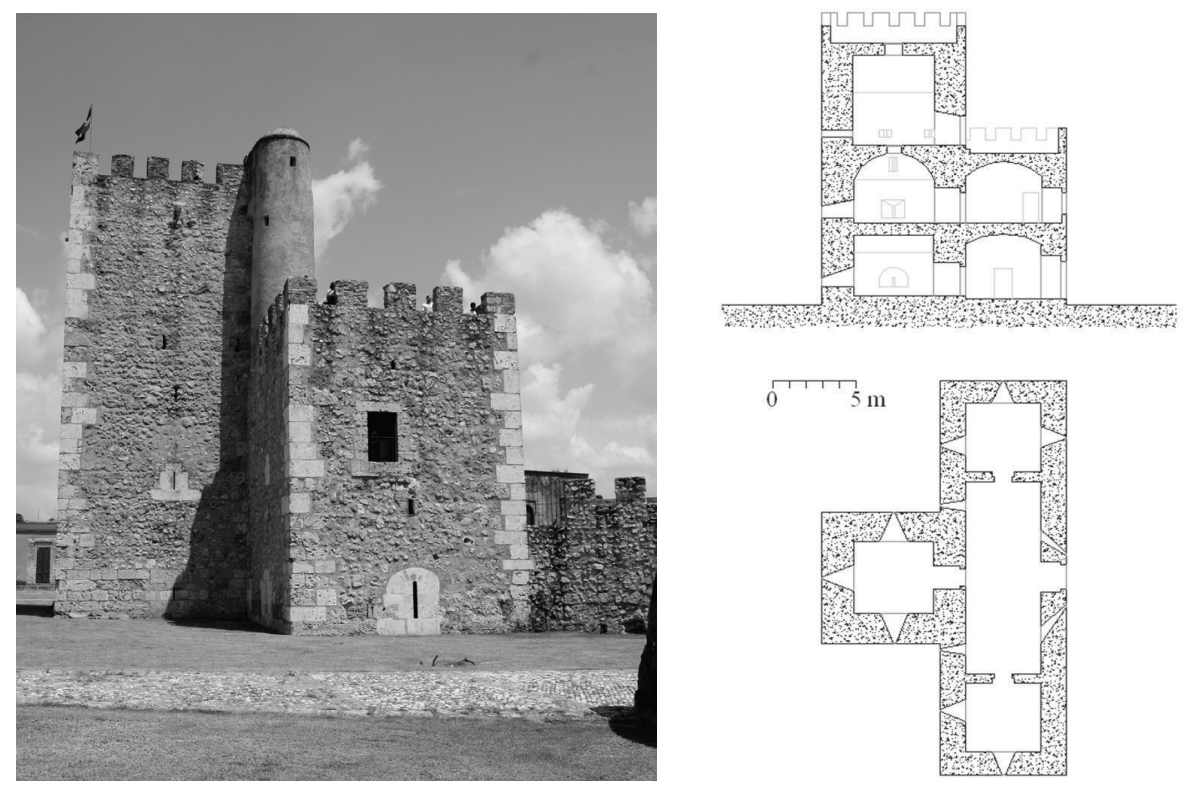

Fuente: Elaborados por el arquitecto español Luis Moyano Molina, residente en Santo Domingo y quien amablemente aportó esta información para la investigación en el 2014.

Figura 9. La "torre-atalaya" de la catedral y el Fortín de la Natividad en Panamá Viejo
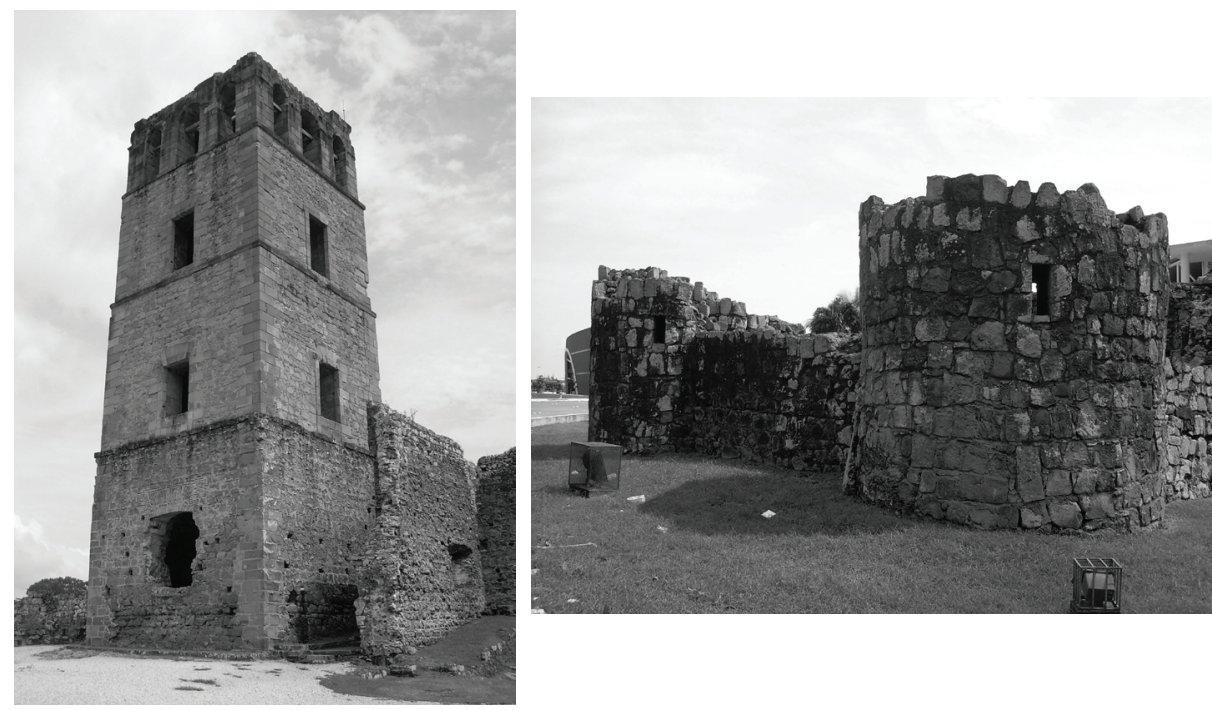

Fuente: Fotografias del autor, diciembre de 2009. 
de los llanos de Bonda. Esto resulta en dos edificios aparentemente similares en tamaño y en técnicas constructivas. En el caso de Santo Domingo, los muros tienen 1,9 $\mathrm{m}$ de espesor en la base para soportar una torre de $19,3 \mathrm{~m}$ de altura. ${ }^{44} \mathrm{Si}$ se aplican estas proporciones al caso de Bonda, resultaría que una torre con $16 \mathrm{~m}$ de altura debería tener muros de al menos $1,7 \mathrm{~m}$ de espesor. ${ }^{45}$

Otros dos referentes pertinentes se encuentran en Panamá Viejo también colonia española (1519): la "torre-atalaya" de la catedral (1619-1626) que servía de vigía para divisar embarcaciones y el Fortín de la Natividad (1616) o principal defensa occidental de la ciudad (Figura 9). La torre de $27 \mathrm{~m}$ de altura tiene muros de $2 \mathrm{~m}$ de espesor en su base y el fortín, cuya altura es incierta por encontrarse en ruina, tiene muros $1,5 \mathrm{~m}$ de ancho. ${ }^{46}$

\section{Las tribus de la Sierra Nevada: vecinos y rivales}

Los cronistas del siglo XVI describieron en esta región a una densa población indígena establecida desde la costa del mar Caribe en el piedemonte serrano hasta casi 2,000 m.s.n.m. ${ }^{47}$ Las principales comunidades descritas eran "Osariona, Taironaca, Orejones, Carbón, Betoma, Pocigüeica, Aruacos, y los fronterizos a Santa Marta” de los cuales Bonda era la más cercana. ${ }^{48}$

Desde el momento del contacto, los españoles diferenciaron a las agrupaciones indígenas ubicadas en la Sierra Nevada y las clasificaron en provincias. Esta clasificación no solo obedeció a la ubicación en el territorio de las agrupaciones y sus principales poblados, sino también a manifestaciones de una cierta homogeneidad cultural al interior de cada una. La característica más evidente de diferenciación cultural entre provincias, identificada por los españoles, consistió en variaciones en los dialectos nativos. ${ }^{49}$ Es importante aclarar que esta organización por provincias establecida por los españoles no necesariamente significa que cada una constituía un cacicazgo. Una provincia no debe considerarse como una unidad política, aunque sí como una agrupación que podía compartir ciertas características culturales

44. Información obtenida de las fotografias, descripciones y levantamiento arquitectónico de la Torre del Homenaje en Santo Domingo, elaborados por el arquitecto español Luis Moyano Molina en 2014.

45. Coignet y Coignet 30-35; Perla y Yáñez 61-73; Schmitt y Heene 163-171.

46. Walo Araújo y Patronato Panamá Viejo, Panamá Viejo: de la aldea a la urbe (Panamá: Patronato Panamá Viejo, 2007) 44, 100 y 110; Eduardo Tejeira Davis, Panamá: guía de arquitectura y paisaje (Panamá y Sevilla: Instituto Panameño de Turismo / Consejería de Obras Públicas y Transportes, 2007) 189-190.

47. Gerardo Reichel-Dolmatoff, Datos histórico-culturales sobre las tribus de la antigua Gobernación de Santa Marta (Bogotá: Imprenta del Banco de la República, 1951) 77; Gerardo Reichel-Dolmatoff, Arqueología de Colombia: un texto introductorio (Bogotá: Imprenta Nacional de Colombia, 1997) 252.

48. Simón 14; Reichel-Dolmatoff, Datos histórico-culturales xi, 55-58 y 61-66.

49. Reichel-Dolmatoff, Datos histórico-culturales 32-33. 
(Figura 10). ${ }^{50}$ En 1573 el gobernador Luis de Rojas le informó al rey que la riqueza de la Corona española podría aumentar dado que allí se encontraba una numerosa población indígena y abundantes minas:

rresultaria que V.M.t [Vuestra Majestad] fuese muy servido y su rreal hacienda acrecentada porque se conquistaría con la dicha gente [unos soldados solicitados] y con lo demás que aquí se pudiese juntar los valles de pocigueica y betoma [poblados indígenas al sur de Santa Marta] que son seis leguas desta ciudad que es la mas rrica tierra de naturales y minas quen todas las indias ay... ${ }^{51}$

Sobre la organización social de las comunidades indígenas, Fray Pedro Simón describió en 1625: "Unos vivían en comunidades sujetas a caciques, y otros derramados en behetrías. Los pueblos pasaban de mil, con caminos enlosados de cuatro y seis leguas; las lenguas muchas". ${ }^{2}$ De Covarrubias define "behetría" como "las villas eximidas de ciudades, que no están sujetas a ningún corregimiento por apelación ni por residencia". ${ }^{3}$ En otras palabras, para los españoles era una forma de organización social sin sujeción a una ciudad en la cual el cacique no es la figura permanente de autoridad y el líder cambia según quien esté en mejores condiciones de serlo ante una necesidad específica, como una situación de guerra. ${ }^{54}$ Para los españoles pudieron percibirlo como desorden por la carencia de un líder permanente y sin un gobernante hereditario, así como un problema al tratar con grupos sin líderes autoritarios o en constante cambio de identidad y pertenencia, dado que no se lograba establecer fácilmente un canal de comunicación o un punto de presión para ejercer control. ${ }^{55}$ En la Sierra Nevada de Santa Marta se presentaron ambas situaciones: los caciques estables eran fáciles de identificar y ser presionados, secuestrados o asesinados para manipular a sus súbditos, ${ }^{56}$ así como el caso de líderes temporales y rápidamente remplazados en sus aldeas que representaron una mayor dificultad para controlar a algunas comunidades indígenas. La autonomía e independencia que según parece tenían los cacicazgos contribuyó a que no tuvieran una unidad política ni militar, lo que fomentó una serie de conflictos entre las comunidades indígenas e incluso llevó a algunas a establecer alianzas con los españoles para enfrentar a sus rivales nativos en el territorio. ${ }^{57}$

50. Carl Langebaek, Poblamiento prehispánico de las bahías de Santa Marta: contribución al estudio de los cacicazgos Tairona del norte de Colombia (Pittsburgh y Bogotá: University of Pittsburgh / Universidad de los Andes, 2005) 26.

51. "Carta del gobernador Luis de Rojas", Santa Marta, 17 de enero de 1573.AGI, Sevilla, Santa Fe, 49 , r. 8 , n. 23, f. 2 v.

52. Simón 272 .

53. De Covarrubias 178.

54. Diccionario de la Real Academia Española.

55. Ferguson y Whitehead 14.

56. Carl Langebaek, Indios y españoles en la antigua provincia de Santa Marta, Colombia: documentos de los siglos XVI y XVII (Bogotá: Ediciones Uniandes, 2007) 59-71.

57. Reichel-Dolmatoff, Datos histórico-culturales 32, 35-36. 
Figura 10. Plano de las provincias indígenas Bonda, Tairona y Betoma durante el siglo XVI

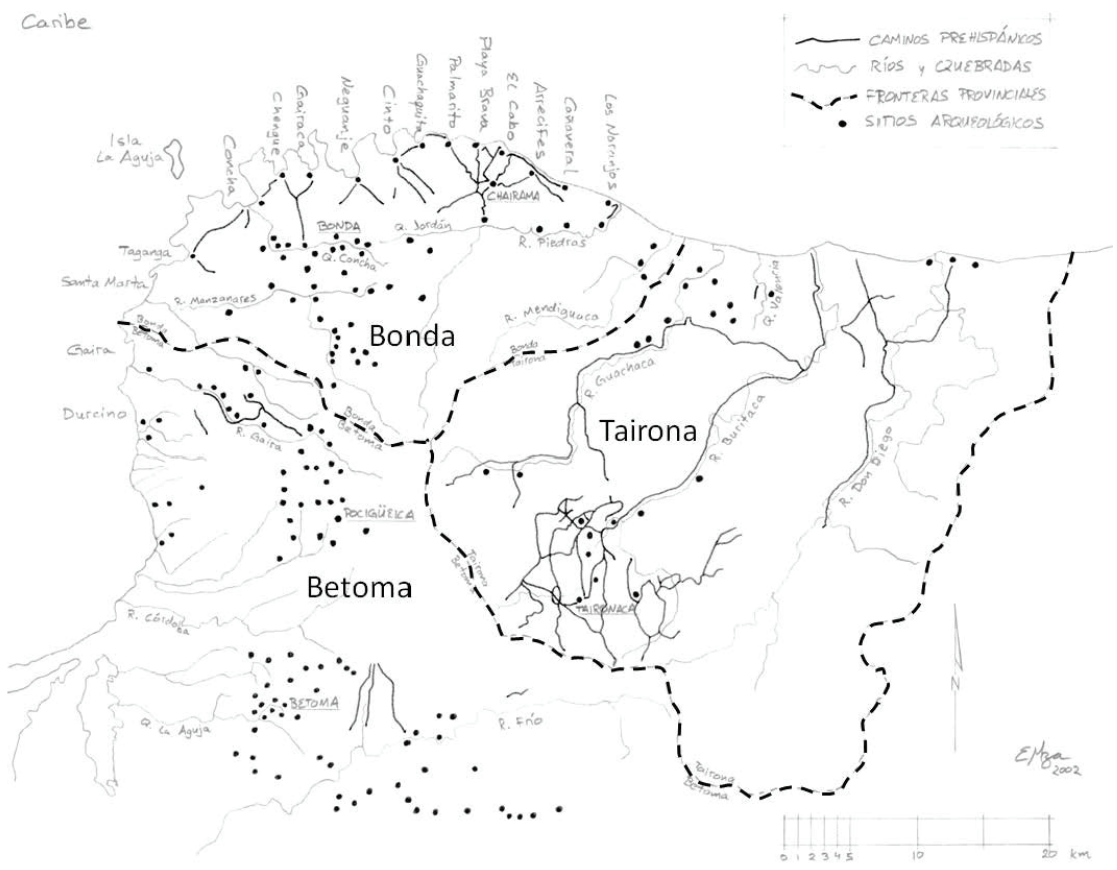

Fuente: Eduardo Mazuera Nieto, Caminos prehispánicos del área tairona: alternativas de su función

(Bogotá: Ediciones Uniandes, 2003).

\section{Una ilusión de control de corta duración}

La fortaleza de Bonda debía funcionar de manera similar a otras casas fuertes de las mismas características, con un cuerpo de guardia compuesto por al menos doce soldados bajo el mando de un capitán, quienes utilizarían la edificación como base de operaciones para realizar entradas en el territorio indígena..$^{58}$ Desde el interior sería posible resistir los ataques de los indios y repelerlos con el disparo de cañones y arcabuces. La construcción nunca debería ser desatendida ni dejada sola; siempre tendría que haber una vigilancia del entorno inmediato para alertar de posibles ataques. ${ }^{59}$

La nueva fortaleza de Bonda fue atacada por los indígenas el mismo año en que fue finalizada su construcción. ${ }^{60}$ Los historiadores Ernesto Restrepo Tirado y Arturo Bermúdez Bermúdez narran los acontecimientos que llevaron a la destrucción de este edificio. ${ }^{61}$ Bajo el mando del cacique Coendo un grupo de indígenas

58. Miranda 112.

59. De Vargas 150-153.

60. Zapatero 84.

61. Restrepo 242 y 243; Bermúdez 221. 
se aproximó a la fortaleza cargando una viga de madera que presentaron como un aporte para la construcción en curso de la casa para la española Ana Ramírez de Manjarrés, heredera de la encomienda en el sector. El cacique Coendo le pidió a Juan Castro, castellano de la fortaleza y administrador de la encomienda, que inspeccionara la viga y verificara su calidad. Castro salió de la fortaleza a su encuentro y cuando se inclinó a revisar la pieza fue ejecutado con un hachazo en la cabeza. Al instante entraron los indígenas al fuerte y mataron a todos sus ocupantes, derruyeron parte de la fortificación y tomaron las riquezas allí almacenadas por los ciudadanos de Santa Marta, quienes esperaban que este fuera un lugar seguro ante el riesgo de ataques piratas. Juan de Ríos, procurador general de Santa Marta, narra las versiones de testigos así:

Casa de Bonda con su guarda y artillería, a media legua del dicho pueblo. Da cuenta de que los indios mataron con animo infernal y diabolico a la persona que estaba en nombre de la ley y otros dos soldados que estaban en la guarda y vela de la fortaleza [...] Y mataron a las indias e indios de servicio que estaban en la fortaleza que eran cristianos [...] tomaron y rrobaron toda la rropa oro y plata que en la dicha fortaleza tenían en guarda y custodia los vezinos desta ciudad y sacaron toda la polvora y artillería municiones y armas quen la dicha fortaleza avia y quitaron toda la paja que avia en los bohíos questavan cerca de la dicha fortaleza y la metieron dentro y la pegaron fuego y la echaron por tierra y con puntales y hachas derribaron las paredes y lo dexaron asolado... ${ }^{62}$

De la cita anterior es interesante destacar la cercanía de bohíos a la fortaleza dado que se trataba de un edificio alejado de Santa Marta, pero que aparentemente no estaba solo. Era común que las casas fuerte en puestos de avanzada proveyeran de protección a los pobladores del territorio ocupado, que podían ser españoles encomenderos o indios bajo su servicio. ${ }^{63}$

En 1573 la fortaleza parcialmente destruida fue atacada nuevamente por los indígenas de Bonda ante la oportunidad que se presentó cuando la mayor parte de los soldados españoles partieron hacia la bahía de Taganga a repeler un desembarco de enemigos franceses y dejaron a unos pocos soldados en la fortaleza. El combate duró dos días hasta que regresaron de Taganga los soldados y los indígenas se retiraron. ${ }^{64}$ El gobernador Luis de Rojas le informó al rey sobre estos ataques así:

Por no perder esta Ciudad y puerto como tengo dho. á V.M.t [Vuestra Majestad] ser de tanta ynportancia visto q. los indios naturales se desvergonzaron a quebrantar la paz y servidumbre y derrivaron y q.maron la fortaleza q. en nombre de V.M.t [Vuestra Majestad] estaba fundada en los llanos de Bonda, y q. mataron la gente q. en su guarda y defensa estaba por rrequerimos q.

62. "Carta de Luis de Rojas con testimonios tomados por Juan de Ríos", Santa Marta, 18 de marzo de 1573. AGN, Bogotá, Sección Colonia, Fondo Caciques e Indios, 48, doc. 6, ff. 160r-160v.

63. Pavón 288-291.

64. Bermúdez 222. 
esta Ciudad y V[ecin]os me hizieron y por verlos en terminos q. se querían despoblar della vyne a fundar y rrehedificar la dha. Fortaleza, en el dho. sitio y lugar en nombre de V.M.t [Vuestra Majestad] rreal..$^{65}$

Los hechos narrados dan cuenta de las acciones tomadas por los indios Bonda hacia la fortaleza española construida "a media legua" de su poblado principal. El registro histórico no presenta explícitamente las versiones de los indígenas o sus opiniones sobre los ataques a la fortaleza, pero sus acciones son una demostración de resistencia hacia la ocupación española.

El 15 de enero de 1574 el Cabildo Secular de Santa Marta solicitó al rey Felipe II recursos económicos para terminar de reconstruir la fortaleza y para dotarla de soldados y municiones que consideraban de vital importancia para la seguridad de la ciudad. La carta afirma que, a pesar del ataque indígena al edificio y el asesinato de cinco soldados, los agresores fueron convocados a deponer las armas y reconocer al rey como su soberano sin que hubiera castigo para ellos, pero estos se negaron a rendirse y continuaron sublevados.

Los naturales rrevelados y de guerra que hizieron el daño y muertes en la fortaleza que en vuestro rreal nombre estaba fundada en los llanos de bonda haviendose tornado a alçar y reedificar por vuestro gobernador Don Luis de Rojas como a vuestra majestad constara por las ynformaciones que en la dicha flota fueron y por las que agora yran con sus dañados y perversos animos volvieron sobre la dicha casa y la cercaron y hizieron guerra de tal horden que flecharon y mataron uno de los soldados que en su guarda y defensa estaban y antes de esto mataron cuatro en el camino y an andado y andan tan soberbios y en la rrebelion aunque an sido y son rogados y llamados por el dicho vuestro presidente con indios amigos y de paz que vuelvan a ella y al señorio y servidumbre rreal y que os rreconoscan por soberano señor y que se les perdonaran sus delitos y guardara con ellos cumplida paz no lo an querido ni quieren hacer sino seguir su dañada y mala voluntad y hacer los daños que pueden.Y si la dicha fortaleza no se ubiera tornado a alçar y rreedificar tenemos por cierto nos ubieran seguido de suerte que ubieran acabado y despoblado y destruido este pueblo y con estar alli la dicha fuerza es freno bastante para que no tengan este atrevimiento y para que aunque se tarde algo vengan a la paz. ${ }^{66}$

Es notoria la afirmación de que, de no haber sido por la fortaleza reconstruida después del primer ataque, seguramente los indígenas hubieran destruido a Santa Marta y que con la presencia del edificio se ejerció un control para que no lo hicieran. A pesar de los reiterados intentos por parte del gobernador Luis de Rojas por reunir los recursos económicos necesarios para la reconstrucción total del fuerte, estos le fueron negados tanto por el gobernador de Cartagena como por el rey de España, hasta finalmente desistir en su iniciativa. Desmantelada y en estado ruinoso,

65. "Carta de Luis de Rojas”, Santa Marta, 20 de abril de 1573. AGI, Sevilla, Santa Fe, 49, r. 8, n. 26, f. 2v.

66. "Carta del Cabildo Secular de Santa Marta", Santa Marta, 15 de enero de 1574. AGI, Sevilla, Santa Fe, 66, n. 13, ff. 1r-1v. 
la fortaleza fue desechada como elemento activo en el sistema defensivo de la ciudad. El obispo de Santa Marta fray Sebastián de Ocando le informó al rey en 1577 que el gobernador Lope de Orozco, "Viendo la importancia de traer a la paz a los indios de Bonda", ordenó la demolición definitiva de lo poco que quedaba en pie de la fortaleza en la que seis soldados estaban dedicados a asaltar a los indígenas para sobrevivir, "los quales hacian mucho mal a los yndios y entiendo queran causa destar alzados". ${ }^{67}$

Aquí se puede apreciar un cambio en la connotación del edificio, de fortaleza oficial a guarida de ladrones. En las fuentes consultadas no hay nuevas menciones de ataques a la fortaleza, pero sí que fue desmantelada por los mismos españoles con el ánimo de apaciguar el malestar generado en la población indígena por su presencia. En la misma carta, Ocando se refiere al anterior gobernador Luis de Rojas como "hombre ya de mucha edad y poco temido de los indios y en effeto no ha hecho ni haze nada en lo que toca a sujetar la tierra". ${ }^{68}$ Tanto la fortaleza de los llanos de Bonda como su constructor Luis de Rojas habían perdido para este momento la importancia, eficacia y utilidad que anteriormente se les adjudicaba. La fortaleza de Bonda, en pocas palabras, se extinguió en forma definitiva.

Para los últimos años del siglo XVI la población indígena de las estribaciones de la Sierra Nevada de Santa Marta, aledaña a esta ciudad, había sufrido una gran disminución no tanto por las guerras como por las enfermedades — viruela, tifus, gripe, difteria y sarampión - traídas de Europa.Tras 28 años de residencia en Santa Marta, el obispo Ocando informó en 1607 que había sido testigo de un descenso en la población indígena que pasó de aproximadamente 20,000 personas a 2,000. ${ }^{69}$ Con la entrada del siglo XVII se afianzaron las encomiendas en la región y no fue necesario volver a defenderse sobre el frente de tierra de Santa Marta, ni esforzarse por controlar un territorio que había perdido su condición de frontera. El antiguo territorio de grandes cacicazgos había sido reducido a pequeñas comunidades indígenas reubicadas en los valles y llanos donde podían ser controlados por los españoles. ${ }^{70}$

En adelante, la atención militar se volcó hacia las defensas inmediatas de la ciudad, enfocadas en contrarrestar los ataques de sus enemigos europeos provenientes del mar. $^{71}$ Muchas otras fortificaciones se construyeron después de la de los llanos de Bonda en diferentes colonias españolas en donde también se pretendió controlar un territorio de frontera. Sin embargo, la forma de estas era diferente y correspondía a la

67. "Carta del obispo fray Sebastián de Ocando", Santa Marta, 12 de febrero de 1577. AGI, Sevilla, Santa Fe, 230, n. 11, f. 1 r.

68. "Carta del obispo fray Sebastián de Ocando", Santa Marta, 12 de febrero de 1577. AGI, Sevilla, Santa Fe, 230, n. 11, f. 1v.

69. "Informe de Sebastián de Ocando", Santa Marta, 30 de mayo de 1607. AGI, Sevilla, Santa Fe, 230, n. 22, ff. 1r-1v.

70. Miranda 89; Lola G. Luna, Resguardos coloniales de Santa Marta y Cartagena y resistencia indígena (Bogotá: Editorial Presencia / Fondo de Promoción de la Cultura del Banco Popular, 1993) 43; Reichel-Dolmatoff, Datos histórico-culturales 36-38.

71. Zapatero 83-89; Bermúdez 222 y 223. 
traza de fuertes abaluartados, además de estar frente al mar o a la orilla de ríos navegables donde podían repeler ataques de enemigos. ${ }^{72}$ Caso muy diferente al de la fortaleza de los llanos de Bonda, retirada de la costa y de las amenazas que llegaban a ella.

\section{Conclusión}

Durante el siglo XVI, la población indígena de Bonda, a $14 \mathrm{~km}$ al oriente de Santa Marta, se interpuso a la expansión de los españoles y su control de esta provincia y las siguientes hacia levante. ${ }^{73}$ La extensión de terreno "llano" era de dominio —al menos conceptual - de los españoles mientras que la "sierra" era "salvaje" y ajena a su control.

Se puede concluir que el lugar era apropiado para la construcción de una casa fuerte que sirviera de hito para la demostración del poder conquistador y, al mismo tiempo, para ser utilizada como resguardo de las tropas españolas ante el rechazo y los ataques por parte de los nativos. La ubicación de la fortaleza de los llanos de Bonda afectó el intercambio comercial y el tránsito de los indígenas en el sector, dado que este puesto de avanzada en territorio enemigo les permitía a los españoles realizar incursiones a los poblados cercanos y regresar rápidamente a un refugio. El intercambio de productos entre tierras altas y bajas tuvo que alterarse y como consecuencia el rechazo por parte de las comunidades nativas creció rápidamente.

Es probable que fuera, para efectos de una buena imagen de las autoridades de Santa Marta ante la Corona española, más conveniente mostrar que la gobernación estaba destinando los recursos monetarios a obras importantes. La scenografía presenta una fortaleza imponente con escudos de armas y en pleno funcionamiento. No sería estratégico para las solicitudes de apoyo económico el mostrar una casa fuerte de menor tamaño sin tantos elementos complementarios, como la que perece revelar la evidencia material de la ruina encontrada. Esta se convierte en fuente de información que permite adjudicarle valor a la presencia del objeto - $\mathrm{O}$ huella- y contribuir a la construcción histórica. ${ }^{74}$

Un trabajo de arqueología histórica podría resolver algunas de las anteriores inquietudes, si se realiza desde el enfoque de la historia cultural. Nuevos datos surgirían de la interpretación de los vestigios materiales en el marco de las sociedades y el tiempo estudiados con información acerca de la vida cotidiana, las costumbres, las relaciones entre personas, objetos y edificios. También aportaría al entendimiento de procesos de transformación al generar información material que es independiente del registro histórico escrito sobre el cual la mayoría de la historia se fundamenta. ${ }^{75}$

72. Servicio Histórico Militar, Cartografía y relaciones históricas de ultramar, t. 5 (Madrid: Servicio Histórico Militar, 1980) 134, 137, 139, 140 y 142.

73. Tovar 75 .

74. Hans Ulrich Gumbrecht, Producción de presencia: lo que el significado no puede transmitir (México: Universidad Iberoamericana, 2005) 11; Frank Ankersmit, "Representación, 'presencia' y experiencia sublime”, Historia y Grafía 27 (2006): 140, 163 y 172; LuisVergara Anderson, "Discusiones contemporáneas en torno al carácter narrativo del discurso histórico”, Historia y Grafía 24 (2005): 19-53.

75. Peter Burke, ¿Qué es la historia cultural? (Barcelona: Paidós, 2006) 47-50; Gil J. Stein, “Introduction:The 
La identidad de un edificio se asocia a una imagen o figura, con forma y volumen específicos, que participa en la constitución de su entorno. La materialización de esta figura representa la reconquista de arquetipos asociados a modos de habitar el territorio en medio de un entorno dinámico y cambiante. Las constancias formales en la arquitectura pueden entenderse como la búsqueda de estabilidad y adaptación del edificio en el entorno. También obedecen a la memoria preservada en el lenguaje y manifestada en estilos arquitectónicos o conjuntos particulares de formas. La arquitectura puede transmitir un mensaje, incluso sin usar palabras, así como la construcción de un edificio con una imagen particular en un lugar específico puede implicar una noción y que algo se haga presente. ${ }^{76}$

La fortaleza de los llanos de Bonda adquiere una connotación de símbolo de autoridad, poder y seguridad para los españoles y reúne en su presencia significados extralingüísticos y nociones asociadas a su origen..$^{77}$ En un "orden de las cosas" propio del siglo XVI, las fortificaciones de la Corona representarían un símbolo de poder legitimado en la historia; su lenguaje arquitectónico sería una forma de semiología visual y material. La reproducción de este tipo arquitectónico, o arquetipo, en un contexto ajeno al europeo refleja la noción, todavía vigente en ese entonces, de un espacio homogéneo y medible con la misma visión de los siglos anteriores. Las fortificaciones medievales en España habían cumplido una función y constituían un "modelo venerable", antiguo y respetado que había demostrado ser confiable y eficaz. ${ }^{78}$ Aquí es posible interpretar la construcción de este tipo de fortaleza como el deseo de traer a Europa al Nuevo Mundo y recrear al edificio bajo los parámetros políticos y culturales delViejo Mundo.

\section{Fuentes}

\section{Manuscritas}

Archivo General de la Nación, Bogotá (AGN)

Fondo Caciques e indios

Archivo General de Indias, Sevilla (AGI)

Audiencia de Santa Fe

Comparative Archaeology of Colonial Encounters", The Archaeology of Colonial Encounters: Comparative Perspectives, ed. Gil J. Stein (Santa Fe: School of American Research Press, 2005) 6.

76. Christian Norberg-Schulz, The Concept of Dwelling: on the Way to Figurative Architecture (New York: Rizzoli, 1985) 29, 30, 111 y 114.

77. Reinhart Koselleck, Futuro pasado. Para una semántica de los tiempos históricos (Barcelona: Ediciones Paidós, 1993) 112-126.

78. Alfred W. Crosby, La medida de la realidad. La cuantificación y la sociedad occidental, 1250-1600 (Barcelona: Crítica / Grijalbo Mondadori, 1998) 11, 15, 21-23, 30-33, 93-95. 


\section{Impresas}

Acosta, Joaquín. Historia de la Nueva Granada. Medellín: Editorial Bedout, 1971. De Aguado, Fray Pedro. Recopilación historial. Bogotá: Imprenta Nacional, 1906.

De Castellanos, Juan. Elegías de varones ilustres de Indias. Bogotá: Editorial Gerardo Rivas Moreno, 1997.

De Covarrubias Orozco, Sebastián. Tesoro de la lengua castellana o española. Madrid: Editorial Castalia, 1995.

De Herrera y Tordesillas, Antonio. Historia general de los hechos de los castellanos en las islas y Tierra Firme del mar océano. Asunción: Editorial Guaranía, 1944.

De Piedrahíta, Fernández. Historia general de las conquistas del Nuevo Reino de Granada. Cali: Editorial Carvajal, 1987.

De Vargas Machuca, Bernardo. Milicia y descripción de las Indias. Bogotá: Biblioteca Banco Popular, 2003.

Fernández de Oviedo, Gonzalo. Historia general y natural de las Indias, islas y TierraFirme del mar océano. Madrid: Editorial Bruño, 1991.

Julián, Antonio. La Perla de la América, Provincia de Santa Marta. Bogotá:Academia Colombiana de Historia, 1980.

Simón, Fray Pedro. Noticias historiales de las conquistas de Tierra Firme en las Indias Occidentales. Bogotá:Talleres Gráficos Banco Popular, 1981.

Tovar, Hermes. Relaciones y visitas a los Andes. Siglo XVI. Región del Caribe. Tomo 2. Bogotá: Colcultura, 1993.

\section{Bibliografía}

Ankersmit, Frank. “Representación, 'presencia' y experiencia sublime”. Historia y Grafía 27 (2006): 139-172.

Araújo, Walo y Patronato PanamáViejo. Panamá Viejo: de la aldea a la urbe. Panamá: Patronato Panamá Viejo, 2007.

Bermúdez Bermúdez, Arturo. Materiales para la historia de Santa Marta. Bogotá: Banco Central Hipotecario / Editorial L. Canal y Asociados, 1981.

Braudel, Fernand. El Mediterráneo y el mundo mediterráneo en la época de Felipe II. México: Fondo de Cultura Económica, 2010.

Bravo Nieto, Antonio y Jesús M. Sáez Cazorla. Melilla en el siglo XVI a través de sus fortificaciones. Melilla: Servicio de Publicaciones del Ayuntamiento / Fundación Municipal Socio-Cultural, 1988.

Burke, Peter. ¿Qué es la historia cultural? Barcelona: Paidós, 2006.

Cadavid, Gilberto y Luisa Fernanda Herrera. "Manifestaciones culturales en el área Tayrona”. Informes Antropológicos 1 (1985): 5-44.

Cámara, Alicia. Fortificación y ciudad en los reinos de Felipe II. Madrid: Nerea, 1998.

Cámara,Alicia y Fernando Cobos. "La experiencia de la monarquía española en la fortificación marítima del Mediterráneo y su proyección en el Caribe”. Actas del Congreso Internacional Fortificación y Frontera Marítima, Ajuntament d'Eivissa, 2005. 
Chueca Goitia, Fernando. Invariantes castizos de la arquitectura española. Madrid: Dossat, 1981.

Coignet, Jean y Laurent Coignet. Restaurar una casa antigua. Construcción, diagnóstico, intervenciones. Barcelona: Ediciones Ceac, 2006.

Crosby, Alfred W. La medida de la realidad. La cuantificación y la sociedad occidental, 1250-1600. Barcelona: Crítica / Grijalbo Mondadori, 1998.

Dorta, Enrique Marco. Historia del arte hispanoamericano. Tomo 1. Barcelona: Salvat Editores, 1956.

Ferguson, R. Brian y Niel L. Whitehead. Eds. War in the Tribal Zone, Expanding States and Indigenous Warfare. Santa Fe: School of American Research Press, 1992.

Gentil Baldrich, José María. "La interpretación de la 'scenografía' vitrubiana o una disputa renacentista sobre el dibujo del proyecto”. EGA: Revista de Expresión Gráfica Arquitectónica 1 (1993): 15-33.

Grabar, Oleg. "La arquitectura del poder: palacios, alcazabas y fortificaciones”. La arquitectura del mundo islámico, su historia y significado social. Ed. George Michell. Madrid: Alianza, 1985.

Gutiérrez, Ramón. Fortificaciones en Iberoamérica. Madrid: Fundación Iberdrola / Ediciones ElViso, 2005.

Gutiérrez, Ramón y Rodrigo Gutiérrez. Historia del arte iberoamericano. Barcelona: Lunwerg, 2000.

Gumbrecht, Hans Ulrich. Producción de presencia: lo que el significado no puede transmitir. México: Universidad Iberoamericana, 2005.

Herrera Ángel, Marta. Ordenar para controlar, ordenamiento espacial y control político en las llanuras del Caribe y en los Andes centrales neogranadinos. Siglo XVIII. Medellín: La Carreta, 2007.

Koselleck, Reinhart. Futuro pasado. Para una semántica de los tiempos históricos. Barcelona: Ediciones Paidós, 1993.

Langebaek, Carl. Indios y españoles en la antigua provincia de Santa Marta, Colombia: documentos de los siglos XVI y XVII. Bogotá: Ediciones Uniandes, 2007. - Poblamiento prehispánico de las bahías de Santa Marta: contribución al estudio de los cacicazgos Tairona del norte de Colombia. Pittsburgh y Bogotá: University of Pittsburgh / Universidad de los Andes, 2005.

Luna, Lola G. Resguardos coloniales de Santa Marta y Cartagena y resistencia indígena. Bogotá: Editorial Presencia / Fondo de Promoción de la Cultura del Banco Popular, 1993.

Mazuera Nieto, Eduardo. Caminos prehispánicos del área tairona: alternativas de su función. Bogotá: Ediciones Uniandes, 2003.

. La fortaleza de los llanos de Bonda. Relación entre edificio y entorno en la frontera de Santa Marta en el siglo XVI.Tesis de Maestría en Historia, Universidad de los Andes, 2014.

Miranda Vásquez, Trinidad. La Gobernación de Santa Marta (1570-1670). Sevilla: Escuela de Estudios Hispanoamericanos, 1976. 
Mora Piris, Pedro. "Arte y técnica en la fortificación”. Las fortificaciones de Carlos $V$. Coord. Carlos José Hernando Sánchez. Madrid: Ediciones del Umbral, 2000.

Norberg-Schulz, Christian. The Concept of Dwelling: on the Way to Figurative Architecture. New York: Rizzoli, 1985.

Pagden, Anthony. Spanish Imperialism and the Political Imagination. Studies in European and Spanish-American Social and Political Theory 1513-1830. New Haven:Yale University Press, 1990.

Pavón Maldonado, Basilio. Tratado de arquitectura hispano-musulmana. Volumen 2. Madrid: Consejo Superior de Investigaciones Científicas, 1999.

Perla, Antonio y Ana Yáñez. Manual de conservación de casas históricas y singulares. Barcelona:Tusquets, 2005.

Reichel-Dolmatoff, Gerardo. Arqueología de Colombia: un texto introductorio. Bogotá: Imprenta Nacional de Colombia, 1997.

. Datos histórico-culturales sobre las tribus de la antigua Gobernación de Santa Marta. Bogotá: Imprenta del Banco de la República, 1951.

Restrepo Tirado, Ernesto. Historia de la provincia de Santa Marta. Bogotá: Biblioteca de Autores Colombianos / Editorial ABC, 1953.

Sánchez Doncel, Gregorio. La presencia de España en Orán (1509-1792). Toledo: Estudio Teológico de San Ildefonso, 1991.

Sánchez-Gijón, Antonio. "La Goleta, Bona, Bugía y África. Los presidios del Reino de Túnez en la política mediterránea del emperador". Las fortificaciones de Carlos V. Coord. Carlos José Hernando Sánchez. Madrid: Ediciones del Umbral, 2000.

Sarcina, Alberto. "Santa María de la Antigua del Darién, delimitación de la ciudad y nuevos hallazgos arqueológicos”. Conferencia, Museo del Oro, 2014.

Schmitt, Heinrich y Andreas Heene. Tratado de construcción. Barcelona: Gustavo Gili, 2002.

Servicio Histórico Militar. Cartografía y relaciones históricas de ultramar. Tomo 5. Madrid: Servicio Histórico Militar,1980.

Stein, Gil J. "Introduction: The Comparative Archaeology of Colonial Encounters". The Archaeology of Colonial Encounters: Comparative Perspectives. Ed. Gil J. Stein. Santa Fe: School of American Research Press, 2005.

Tejeira Davis, Eduardo. Panamá: guía de arquitectura y paisaje. Panamá y Sevilla: Instituto Panameño de Turismo / Consejería de Obras Públicas y Transportes, 2007.

Vergara Anderson, Luis. "Discusiones contemporáneas en torno al carácter narrativo del discurso histórico". Historia y Grafía 24 (2005): 19-53.

Vilar, Juan Bautista. Mapas, planos y fortificaciones hispánicos de Libia (1510-1911). Madrid:Agencia Española de Cooperación Internacional, 1997.

- Mapas, planos y fortificaciones hispánicos de Túnez (S XVI-XIX). Madrid: Instituto de Cooperación con el Mundo Árabe, 1991.

Villena, Leonardo. "Libros sobre fortificaciones: la circulación de los saberes técnicos". 
Las fortificaciones de Carlos V. Coord. Carlos José Hernando Sánchez. Madrid: Ediciones del Umbral, 2000.

Zapatero, Juan Manuel. Historia de las fortalezas de Santa Marta y estudio asesor para su restauración. Bogotá:Academia Colombiana de Historia / Carlos Valencia Editores, 1980. 